\title{
Prescribing vitamins at primary health care level: Exploration of facts, factors and solution
}

\author{
Adhir Kumar Das and Md. Sayedur Rahman
}

Department of Pharmacology, Bangabandhu Sheikh Mujib Medical University, Shahbag, Dhaka, Bangladesh.

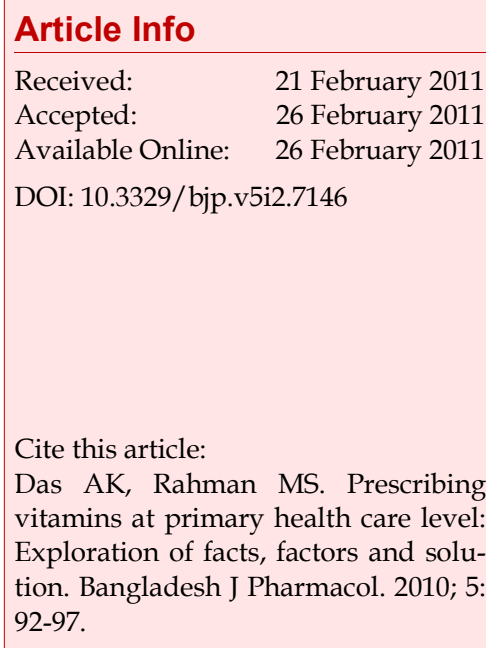

\begin{abstract}
The impact of educational intervention on prescribing trend of vitamins at primary health care level was investigated by analyzing 2000 prescriptions containing vitamins. Prevalence of vitamin prescribing was 30.2, 38.7 and $45.4 \%$ and contribution of vitamins in the cost of drugs prescribed in vitamin containing prescription was 27.6, 30.4 and $41.9 \%$ at Upazilla Health Complexes (UHC), non-government organizations (NGO) and private practices $(\mathrm{PP})$ respectively. Both parameters significantly $(\mathrm{p}<0.001)$ decreased after intervention. Prescribing of single vitamin preparations was 3.8, 13.9 and $7.8 \%$ and appropriateness of the vitamin prescribing was 14.6, 24.1 and $14.8 \%$ at UHC, NGO and PP respectively. Both parameters significantly $(\mathrm{p}<0.001)$ increased after intervention. Negligible emphasis on vitamin in pharmacology teaching at MBBS level was observed. Dependency on promotional materials of manufacturers were changed after intervention. In conclusion, knowledge deficiency due to inadequate professional training and dependency on biased information perhaps contributed in irrational prescribing of vitamins.
\end{abstract}

\section{Introduction}

The physicians have been prescribing vitamins for different reasons since hundred years. Since 1982, only few vitamin preparations were available in Bangladesh, of which majority were single ingredient preparations [Drug (Control) Ordinance, 1982]. People were being satisfactorily treated with those vitamins. Though information relating role of multivitamins in disease prevention is weaker than the individual vitamins (Rosenberg, 2007), multivitamin prescribing has became popular since its availability (Rock, 2007). Bangladesh is neither an exception, the consumption of vitamin has increased recently in Bangladesh (IMS, 2006), which perhaps resulted as consequence of entry of multivitamin into the market (BDNF, 2006). The growth of vitamin market is difficult to rationalize only on the basis of nutritional status of the people, as there was no sudden change in that situation.
In Bangladesh, people usually take thiamin and niacin more than their daily requirements (Jahan and Hossain, 1998a), though riboflavin and vitamin C deficiency were observed in few people (Jahan and Hossain, 1998b). In deficiency of specific vitamin, that particular vitamin might be prescribed in individual cases (Wirth, 2006). However, vitamin prescribing has increased significantly without confirmation of specific deficiency or evidence of lack of specific vitamin in the diets of the people (Anonymous, 2006). Prescribing of vitamins in this manner offers little or no benefit to the recipients, rather causes excessive intake of prescribed vitamins, which might even become harmful (NIH, 2006).

Different studies revealed controversial facts about the status of vitamin in clinical medicine (Tribble, 1999; Omenn et al., 1996; Leppala et al., 2000; Stanner et al., 2004; Huang et al., 2006; Bleys et al., 2006). The teaching of pharmacology in undergraduate medical curriculum 
is mostly drug centered and the number of hours spent on teaching therapeutics is very low when compared to pharmacology (BMDC, 2002; Rahman, 1995). In the undergraduate medical course, vitamins are taught in different subjects though not in detail. Therefore, the pharmacological issues related to vitamins should be taught and evaluated in detail in the course of pharmacology. Moreover, the skill to critically appraise the scientific evidences is not properly achieved by the physicians during their undergraduate program. Consequently, the prescribers mostly depend on advertisement and literature of the pharmaceutical manufacturers rather than scientific articles (Rahman et al., 1999). Thus, the physicians are prone to the influences of the industries and therefore, often prescribe inappropriately.

As the resource of the people of Bangladesh to purchase drugs is limited, wastage of money for inappropriate vitamin prescriptions would make them unable to procure the core, essential and life saving drugs. Consequently, their suffering from different morbidities might be prolonged. Educational interventions like academic detailing and feedback, regulatory interventions like provision of guidelines and different managerial interventions were found successful regarding improvement of prescribing (Arhinful et al., 1996; Islam et al., 2007).

Considering the above facts, the present study was designed to analyze the prescribing trend of vitamins at primary health care level, i.e., Upazilla level. Initially, a baseline survey was conducted, then the reason behind such practice was investigated and finally according to the findings of the investigation, an educational intervention was designed to improve the vitamin prescribing habit. Finally the impact of the educational intervention on different aspects of vitamin prescribing was evaluated.

\section{Materials and Methods}

A comparative study was carried out from August, 2005 to July, 2006 in purposively selected four Upazillas, two from Dhaka and two from Barisal district. From every Upazilla, three types of health care providing facilities, e.g., Upazilla Health Complex (UHC), non-government organizations (NGOs) and private practices (PP) were selected.

Data collection method: Two sets of data, i.e., one retrospective set and one prospective (current) set were collected from the UHCs and NGOs to minimize the limitations of socially biased prescribing. However, in case of PP, due to unavailability of retrospective data, only one set of prospective (current) data was collected. The retrospective data were obtained from the treatment records of the outpatient medical registers of the UHCs and NGOs. The prospective prescriptions were collected from pharmacies, from patient or from their attendants outside the Upazilla Health Complex campus, NGO campus or private chambers while they leave the area. After collecting the prescribing information, an in-depth interview and questionnaire survey was executed among the prescribers of the facilities. Through these surveys, perception of prescriber about appropriateness of vitamin prescribing was assessed by comparing the mentioned indications with that of BDNF (BDNF, 2006). In addition, their commonly consulted sources of information were enquired in the same survey.

Sample size: Before intervention, from UHC and NGO of each study area, 200 prescriptions containing vitamins; 100 from prospective sample, 100 from retrospective sample were collected. From private practitioners of each Upazilla, 100 prescriptions containing vitamins were collected prospectively for the study.

Therefore, the total sample size was 2000, i.e.,

$\mathrm{UHC}=100 \times 2 \times 4=800 ; \mathrm{NGO}=100 \times 2 \times 4=800$ and $\mathrm{PP}=100 \times 4=400$

Criteria for inclusion: Prescriptions of all graduate prescribers (MBBS or equivalent degree) working at that facilities (UHCs and NGOs) and the graduate (MBBS or equivalent degree) Private Practitioners practicing at that Upazillas.

Criteria for exclusion: Prescriptions of the physicians with post-graduation degree in any specialty.

Prescribers of the study: Total 30 prescribers were included in this study. Nine, seven, six and eight prescribers were from Keranigonj, Dhamrai, Wazirpur and Bakergonj Upazilla respectively. Thirteen prescribers were working in UHC, six in NGO and 11 were private practitioners.

Percentage of prescriptions containing vitamin: Number of prescriptions containing vitamins divided by total number of prescriptions required to get that number of prescriptions containing vitamins, multiplied by 100 .

Proportion of prescriptions containing single vitamin preparation: Number of prescriptions containing single vitamins divided by total number of prescriptions containing vitamins multiplied by 100 .

Proportion of appropriate prescribing of vitamins: The indications for which vitamins were prescribed were listed and then categorized as appropriate after comparing them with the list of appropriate indications prepared for the study.

Indications for vitamin prescribing mentioned in Bangladesh National Formulary (BDNF) and British National Formulary (BNF) were compiled, and indications those were common to both documents were considered appropriate for the present study.

Perception of prescribers about appropriateness in vitamin prescribing: Prescribers were asked to mention the indications for which they consider vitamin prescribing 
is required. Later the mentioned conditions were compared with list of appropriate indications prepared for the study as described above.

Contribution of vitamins on cost of prescribed drugs: Unit cost of each drug in a prescription was calculated from BDNF considering the cheapest price of that particular drug. Total cost of the drugs and that of the vitamin preparations in a prescription were calculated.

Proportion of cost shared by vitamins $=$ Total cost of vitamin preparations of prescriptions divided by the total cost of the drugs mentioned in those prescription multiplied by 100 .

Sources of drug information consulted by the prescribers: Name of the sources of drug information was asked to every prescriber, recorded and finally expressed as proportion of the total.

Weightage on vitamins in pharmacology courses: Weightage on vitamins was calculated by dividing the allocated teaching time on vitamin in lecture, tutorial or practical, by the total time allocated in that type of teaching in Pharmacology as mentioned in the Undergraduate Medical Curriculum of 1988 and 2002.

Weightage on vitamins in pharmacology written questions: Weightage on vitamins was calculated by dividing the marks allocated on vitamin in written questions of Pharmacology \& Therapeutics under the University of Dhaka, University of Chittagong and Rajshahi University during the period extending from 1996 to 2005 by the total marks of those written examinations respectively.

After data collection through above-mentioned methodology, an educational intervention designed on the basis of the baseline findings was executed. After execution of the intervention, another set of data (2000 prescriptions) was collected.

Description of the intervention: Step I (Focus group discussion and feedback strategy): According to the convenience of the UH \& FPO of the concerned upazilla, a Focus Group Discussion (FGD) was arranged with the UH \& FPO in the chair and all prescribers of that UHC as participant. In every facility, two sub groups were arranged for FGD. First, the researcher introduced himself as facilitator and requested the participants to introduce themselves. The objectives of the discussion were described. Then the researcher informed them about the required information and the plan of utilization of the obtained information. The before intervention data were disseminated to the prescribers during FGD as a component of the feedback strategy. The responses of the participants were written down and summarized. All summarized information compiled together and the validity of the information was verified. The FGD with feedback strategy were arranged in all the facilities with more than one prescriber and for the remaining, feedback was provided as one-to-one discussion.

Step II (Face-to-face discussion with academic detailing): Face-to-face discussion was conducted with individual prescribers at their official or personal chamber to explain the present scientific evidences and understanding about the vitamins. Academic detailing was conducted by providing one package of printed scientific publications to the prescribers that contains scientific evidences about the recent status of vitamin in different clinical conditions. Face-to-face discussion with academic detailing was conducted among all 30 prescribers of all categories of facilities.

Step III (Reminder strategy): The key information revealed through the baseline survey and other scientific researches conducted earlier were then compiled. This summarized key information was then printed on a Desk Calendar in consultation with communication expert. The Desk Calendar was expected to be kept on the desk of the prescriber to remind them about the discussion and opinion shared. The mobile phone number of the investigator was printed on the Desk Calendar as well as provided to the prescribers. The prescribers were requested to enquire, whatever information they feel needed to prescribe vitamin.

\section{Results}

Table I shows that prescriptions contain vitamins before intervention at UHC, NGO and PP were 30.2, 38.7 and $45.4 \%$ respectively, which was reduced to $20.2,21.8$ and $28.4 \%$ after intervention. The difference was highly significant $(\mathrm{p}<0.001)$. Proportion of prescription containing single vitamin preparations were $2.1,13.9$ and $4.8 \%$, which increased to $51.1,50.3$ and $23.0 \%$ after intervention. The difference was highly significant $(p<0.001)$. Vitamins were prescribed appropriately in $14.6,24.1$ and $14.8 \%$ of the prescriptions, which improved to 58.0, 53.9 and $82.3 \%$. The improvement in appropriateness in vitamin prescribing was highly significant $(p<0.001)$. Vitamins contributed 27.6, 30.4 and $41.9 \%$ of the total cost of prescribed drugs and that was reduced to $20.0,19.6$ and $18.0 \%$ after intervention. The difference was highly significant $(\mathrm{p}<0.001)$.

Forty-five clinical conditions were mentioned by the prescriber as appropriate indication, which was significantly $(p<0.001)$ reduced to 19 clinical conditions after intervention. Furthermore, among the mentioned indications before intervention, only $35.6 \%$ was found to be supported by evidence, which was significantly $(p<0.001)$ higher, i.e., $89.5 \%$ after intervention.

Table II showed the comparison between the source of information on vitamins regularly consulted by the prescribers before and after intervention. Among the prescribers, BDNF was regularly consulted by $16.7 \%$ prescriber before intervention, which was increased to 
Table I

Impact of educational intervention on vitamin prescribing

\begin{tabular}{|c|c|c|c|c|}
\hline & Type of facility & Before intervention & After intervention & $p$ value \\
\hline \multirow[t]{3}{*}{$\begin{array}{l}\text { Proportion of prescriptions contain- } \\
\text { ing vitamin }\end{array}$} & UHC & $\begin{array}{r}30.2 \% \\
\left(800 / 2652^{*}\right)\end{array}$ & $\begin{array}{r}20.2 \% \\
(800 / 3957)\end{array}$ & \multirow[t]{12}{*}{$<0.001$} \\
\hline & NGO & $\begin{array}{r}38.7 \% \\
(800 / 2068)\end{array}$ & $\begin{array}{r}21.7 \% \\
(800 / 3677)\end{array}$ & \\
\hline & PP & $\begin{array}{r}45.4 \% \\
(400 / 882)\end{array}$ & $\begin{array}{r}23.4 \% \\
(400 / 1711)\end{array}$ & \\
\hline \multirow[t]{3}{*}{$\begin{array}{l}\text { Proportion of prescription containing } \\
\text { single vitamin preparations }\end{array}$} & UHC & $\begin{array}{r}3.8 \% \\
(30 / 800)\end{array}$ & $\begin{array}{r}51.1 \% \\
(409 / 800)\end{array}$ & \\
\hline & NGO & $\begin{array}{r}13.9 \% \\
(111 / 800)\end{array}$ & $\begin{array}{r}50.3 \% \\
(402 / 800)\end{array}$ & \\
\hline & PP & $\begin{array}{r}7.8 \% \\
(31 / 400)\end{array}$ & $\begin{array}{r}23.0 \% \\
(92 / 400)\end{array}$ & \\
\hline \multirow[t]{3}{*}{$\begin{array}{l}\text { Appropriateness of vitamin prescrib- } \\
\text { ing }\end{array}$} & UHC & $\begin{array}{r}14.6 \% \\
(117 / 800)\end{array}$ & $\begin{array}{r}58.0 \% \\
(464 / 800)\end{array}$ & \\
\hline & NGO & $\begin{array}{r}24.1 \% \\
(193 / 800)\end{array}$ & $\begin{array}{r}53.9 \% \\
(431 / 800)\end{array}$ & \\
\hline & PP & $\begin{array}{r}14.8 \% \\
(59 / 400)\end{array}$ & $\begin{array}{r}82.3 \% \\
(329 / 400)\end{array}$ & \\
\hline \multirow{3}{*}{$\begin{array}{l}\text { Contribution of vitamins on cost of } \\
\text { prescribed } \\
\text { drugs }\end{array}$} & UHC & $27.6 \%$ & $20.0 \%$ & \\
\hline & NGO & $30.4 \%$ & $19.6 \%$ & \\
\hline & $\mathrm{PP}$ & $41.9 \%$ & $18.0 \%$ & \\
\hline
\end{tabular}

\section{Table II}

Impact of educational intervention on regular consultation of different sources of drug information by the prescribers $(n=30)$

\begin{tabular}{|lcc|}
$\begin{array}{l}\text { Sources consulted regular- } \\
\text { ly }\end{array}$ & $\begin{array}{c}\text { Before } \\
\text { intervention } \\
(\%)\end{array}$ & $\begin{array}{c}\text { After } \\
\text { intervention } \\
(\%)\end{array}$ \\
\hline BDNF & 16.7 & $73.3^{\mathrm{a}}$ \\
Textbook & 66.7 & $100^{\mathrm{a}}$ \\
Medical representatives & 80.0 & $100^{\mathrm{b}}$ \\
and literatures of manufac- & & \\
turers & & \\
Senior colleagues & 16.7 & $40.0^{\mathrm{b}}$ \\
Prescriber's guide & 36.7 & $53.3^{\mathrm{b}}$ \\
Scientific journals & 30.0 & 30.0 \\
Seminars and workshop & 16.7 & 16.7 \\
Internet & 6.7 & 6.7 \\
ap $<0.001$, highly significant; bp $<0.01$, significant & \\
\hline
\end{tabular}

$73.3 \%$ after intervention and the difference was highly significant $(p<0.001)$. Textbook consultation increased from 66.7 to $100 \%$ after intervention and the difference was highly significant $(\mathrm{p}<0.001)$. Eighty percent prescribers consulted medical representatives and literature of pharmaceuticals before intervention and this practice has significantly $(p<0.01)$ increased to $100 \%$ after intervention. Consultation with senior colleagues for drug information has significantly $(p<0.05)$ increased from 16.7 to $40.0 \%$ after intervention. Use of Prescriber's guide increased from 36.7 to $53.3 \%$, however the difference was not statistically significant $(\mathrm{p}>0.05)$. Proportion of physicians consulted scientific journals $(30.0 \%)$, attended seminars and workshops $(16.7 \%)$ and used internet $(6.7 \%)$ have not changed after intervention.

The allocation of teaching time for vitamins was $1.1 \%$ of the total time allocated for the lecture schedule of Pharmacology course mentioned in the Curriculum for Undergraduate Medical Education in Bangladesh 1988 and reduced to $1.0 \%$ in 2002 . In case of tutorial and practical classes no time $(0.0 \%)$ was allocated for these purposes.

Questions on vitamins appeared in the pharmacology written questions of 2nd professional MBBS examinations were $0.8,1.6$ and $1.1 \%$ in the University of Dhaka, University of Chittagong and Rajshahi University respectively. The term "weightage" means the proportion of written questions given from a specific area like vitamin. Every question was counted as a separate entity.

\section{Discussion}

This study was conducted among medical graduates working at primary health care facilities of purposively selected four upazillas. Prevalence of vitamin prescribing among 3 types of facilities was high and varied. The prevalence observed in this study is much higher than the results obtained in the previous study 
conducted in Dhaka metropolitan city (Roy et al., 1995). The intervention of the present study has reduced the prevalence of vitamin prescribing in UHCs, NGOs and PPs. The reduction possibly reflects the positive attitude of the prescribers regarding change in vitamin prescribing. In few studies conducted earlier, NGOs having 'revolving drug fund' system were found to have good prescribing trend (Umenai and Narula, 1999; Okumura and Umenai, 2004), however the present study revealed that prevalence of vitamin prescribing in NGOs was higher than that of UHCs both before and after intervention. The reason might be the absence of 'revolving drug fund' or any other managerial system directed towards improving drug use in the NGOs studied in this present study.

Prescribing of single vitamin preparations were very low in UHCs, which might be due to inadequate time to diagnose specific vitamin deficiency as well as supply of combination vitamin preparation in UHCs. Prescribing of single preparations increased after intervention in all facilities which might be explained by effort of the prescribers to diagnose specific vitamin deficiency as well as improvement in the vitamin supply.

Appropriate prescribing of vitamins was low in all facilities, however NGOs were performing a little better than others. Appropriateness of prescribing increased after intervention in all facilities. However, that is more marked in case of PPs, who responded better perhaps because of their freedom to prescribe independently. Increased prescribing of single vitamin preparations also contributed in improving the appropriateness in vitamin prescribing.

Common clinical conditions for vitamin prescribing as mentioned by the prescribers were inappropriate in two third cases. This reflects that prescribers are unaware about the scientific evidences related to vitamin prescribing. The executed educational intervention leads to reduction in the total number of mentioned indications reflecting improvement in the understanding of prescribers by eliminating the wrong indications from their memory. The increase in the proportion of evidence based indications reveal the fact that prescribers have intention to prescribe on the basis of scientific evidences and are eager to know about their practice.

Regarding the source of information on vitamins among the prescribers, the eighty percent of the prescribers were dependent on the medical representatives and the literature of pharmaceuticals; two-third of the prescribers said that they used textbooks. Only onesixth of the prescribers used BDNF, which reflects poor reputation of BDNF as a source of drug information. About one-third prescribers used scientific journals and few prescribers attended the seminars and workshops. There was a general improvement regarding use of different sources of drug information by the prescribers, which was particularly observed in case of BDNF, textbook and prescriber's Guide. This might be due to persuasion of investigator in favor of reliable source of drug information in place of biased sources. The results of the present study reinforce the observations of the previous studies of similar nature (Mugford et al., 1991; Guiscafre et al., 1997; Suryawati, 2004; Islam et al., 2007; Chowdhury et al., 2007).

Vitamin received very little importance in medical curricula, reflected by only one lecture on this issue in Pharmacology. The lack of weight on vitamin also reflected in evaluation, which corresponds with the evidences published earlier (Begum et al., 1999). Though vitamins are taught in different subjects at undergraduate medical courses like Biochemistry, Community Medicine and Internal Medicine, however the pharmacotherapeutic aspects of vitamins required to be known for vitamin prescribing such as pharmacokinetic profile, mechanism of action, indication, dose, duration and adverse effects of vitamins should be taught and evaluated in the course of pharmacology.

\section{Conclusion}

This can be stated that lack of adequate emphasis on vitamins in the medical curricula, lack of reliable source of information, dependency on biased and incomplete information provided by the pharmaceuticals, availability of unnecessary and unscientific combination vitamin preparations in the market collectively contributed to make the prescriber vulnerable to prescribe vitamins inappropriately. The success of educational intervention with feedback \& reminder rather proved that knowledge deficiency might have played important role in inappropriate prescribing of vitamins.

\section{References}

Anonymous. Cancer and chronic disease in a: A systematic review for a National Institute of Health state-of-the-science conference. Ann Int Med. 2006; 145: 372-85.

Arhinful DK, Das AM, Hadiyono JP et al. How to use applied qualitative methods to design drug use interventions. INRUD Social Scientist Working Group, 1996.

Bangladesh Medical \& Dental Council (BMDC). Curriculum of Pharmacology \& Therapeutics Course for undergraduate medical students of Bangladesh. In: Curriculum for Undergraduate Medical Education in Bangladesh 2002. Compiled and edited by Center for Medical Education, Mohakhali, Dhaka. Approved by Bangladesh Medical and Dental Council, 2002, pp 170-205.

Bangladesh National Formulary. Directorate of Drug Administration, Bangladesh Medical Association, Bangladesh Pharmaceutical Society. Dhaka, 2006, pp 456-66. 
Begum M, Rahman MS, Islam AFMS, Khan IA, Akhter N. Eleven Years of the Undergraduate Medical Curriculum 1988: Review on the Changes in Pharmacology Written Questions. Bangladesh J Physiol Pharmacol. 1999; 15: 27-30.

Bleys J, Miller ER 3 ${ }^{\text {rd }}$, Pastor-barriuso R, Appel LJ, Guallar E. Vitamin-mineral supplementation and the progression of atherosclerosis: A meta-analysis of randomized controlled trials. Am J Clin Nutr. 2006; 84: 880-87.

Chowdhury AKA, Rahman MS, Faroque ABM. Studying and implementing the monitoring-training-planning strategy to ensure the rational use of injections in the hospitals of the Upazila Health Complexes of Bangladesh. Report of the 2007 Safe Injection Global Network (SIGN) annual meeting. WHO, Geneva, 2007, pp 13-14.

Drug (Control) Ordinance 1982. Bangladesh Gazette, Extraordinary. No. 354. Government of the Peoples Republic of Bangladesh, Dhaka, 1982.

Guiscafre H, Martinez H, Reyes H, Perez-Ceuvas R, Castro R, Mufioz O, Gutierrez G. Impact of educational strategy for physicians to improve treatment practices of common diseases. Presented in the first international conference on improving use of medicine, Chiang Mai, Thailand. Essential Drug Monitor. 1997; 23: 6-12.

Huang HY, Caballero B, Chang S, Alberg AJ, Semba RD, Schneyer CR, Wilson RF, Cheng TY, Vassy J, Prokopowicz G Barnes GJ 2nd, Bass EB. The efficacy and safety of multivitamin and mineral supplement use to prevent cancer and chronic disease in adults: A systematic review for a National Institute of Health state-of-the-science conference. Ann Intern Med. 2006; 145: 372-85.

International Medical Statistics (IMS). Switzerland; $1^{\text {st }}$ Quarter: Therapeutic class, Summary Table I, 2006, p 1.

Islam MS, Rahman MS, Misbahuddin M. Impact of prescription audit \& feedback on pattern of prophylactic antimicrobials in caesarean section: A cost reduction perspective. Bangladesh J Physiol Pharmacol. 2007; 23: 1-9.

Jahan K, Hossain M. Pattern of nutrient intake in Bangladesh. In: Nature and extent of malnutrition in Bangladesh. Bangladesh National Nutrition Survey. 1998a, part-1, pp 2848.

Jahan K, Hossain M. Nutrition requirement and deficiency in intake. In: Nature and extent of malnutrition in Bangladesh. Bangladesh National Nutrition Survey, 1998b, part-1 pp 4963.

Leppala JM, Virtamo J, Fogelholm R, Huttunen JK, Albanes D,
Taylor PR, Heinonen OP. Controlled trial of a-tocopherol and $\beta$-carotene supplements on stroke incidence and mortality in male smokers. Arterioscler Thromb Vas Biol. 2000; 20: 230-35.

National Institute of Health (NIH). Multivitamin/Mineral Supplements and Prevention of Chronic Disease; May, 2006: Evidence Report (Publication No. 06-E012).

Okumura J, Umenai T. Impact of Bamako type revolving drug fund on drug use in Vietnam. Presented in the Second International Conference on Improving Use of Medicine, Chiang Mai, Thailand, April 2004.

Omenn GS, Goodman GE, Thornquist MD, Balmes J, Cullen MR, Glass A, Keogh JP, Meyskens FL, Valanis B, Williams $\mathrm{JH}$, Barnhart S, Hammar S. Effect of a combination of betacarotene and vitamin A on lung cancer and cardiovascular disease. N Engl J Med. 1996; 334: 1150-55.

Rahman MS, Begum M, Haque MZ, Akhter N. Drug advertisement in medical journals: A Commentary. Bangladesh J Physiol Pharmacol. 1999; 15: 31-36.

Rahman MS. Changes required in pharmacotherapy teaching to ensure rational use of drugs. Bangladesh J Physiol Pharmacol. 1995; 11: 38-39.

Rock CL. Multivitamin-multimineral supplements: Who uses them? Am J Clin Nutr. 2007; 85: 277S-95S.

Rosenberg $\mathrm{IH}$. Challenges and opportunities in the translation of the science of Vitamins. Am J Clin Nutr. 2007; 85 (suppl): 325S-27S.

Roy J, Saha P, Hossain A, Ahmed M, Choudhury C. Prescription patterns and the use of drugs. JOPSOM. 1995; 14: 6-9.

Stanner SA, Hughes J, Kelly CN, Buttriss J. A review of the epidemiological evidence for the 'anti-oxidant hypothesis'. Public Health Nutr. 2004; 7: 407-22.

Suryawati S. Using the MTP approach to reduce inappropriate use of antibiotics in hospitals: Results of the field test. Presented in the Second International Conference on Improving Use of Medicine, Chiang Mai, Thailand, April 2004.

Tribble DL. Anti-oxidant consumption and risk of coronary heart disease: Emphasis on vitamin C, vitamin E and betacarotene. Circulation 1999; 99: 591-95.

Umenai T, Narula IS. Revolving drug fund: A step towards health security. Bull World Health Organ. 1999; 77: 167-71.

Wirth R. Vitamins and trace elements in nutrition. Update 2005. Med Klin (Munich). 2006; 101: 163-66. 